\title{
Pathogenicity and Volatile Nematicidal Metabolites from Duddingtonia flagrans against Meloidogyne incognita
}

\author{
Xiaoyu Mei, Xin Wang * and Guohong Li * \\ State Key Laboratory for Conservation and Utilization of Bio-Resources in Yunnan, and Key Laboratory for \\ Southwest Microbial Diversity of the Ministry of Education, Yunnan University, Kunming 650032, China; \\ 15808859550@139.com \\ * Correspondence: xinwang2@ynu.edu.cn (X.W.); ligh@ynu.edu.cn (G.L.)
}

check for

updates

Citation: Mei, X.; Wang, X.; Li, G.

Pathogenicity and Volatile

Nematicidal Metabolites from

Duddingtonia flagrans against

Meloidogyne incognita. Microorganisms

2021, 9, 2268. https://doi.org/

$10.3390 /$ microorganisms 9112268

Academic Editors: Carlos

García-Estrada and Carlos Barreiro

Received: 29 September 2021

Accepted: 29 October 2021

Published: 31 October 2021

Publisher's Note: MDPI stays neutral with regard to jurisdictional claims in published maps and institutional affiliations.

Copyright: (c) 2021 by the authors. Licensee MDPI, Basel, Switzerland. This article is an open access article distributed under the terms and conditions of the Creative Commons Attribution (CC BY) license (https:// creativecommons.org/licenses/by/ $4.0 /)$.

\begin{abstract}
Plant parasitic nematodes, especially parasitic root-knot nematodes, are one of the most destructive plant pathogens worldwide. The control of plant root-knot nematodes is extremely challenging. Duddingtonia flagrans is a type of nematode-trapping fungi (NTF), which produces three-dimensional adhesive networks to trap nematodes. In this study, the pathogenicity and volatile organic compounds (VOCs) of the NTF D. flagrans against the plant root-knot nematode, Meloidogyne incognita, were investigated. The predatory process of D. flagrans trapping $M$. incognita was observed using scanning electron microscopy. Gas chromatography-mass spectrometry analysis of the VOCs from D. flagrans led to the identification of 52 metabolites, of which 11 main compounds were tested individually for their activity against $M$. incognita. Three compounds, cyclohexanamine, cyclohexanone, and cyclohexanol, were toxic to M. incognita. Furthermore, these three VOCs inhibited egg hatching of $M$. incognita. Cyclohexanamine showed the highest nematicidal activity, which can cause $97.93 \%$ mortality of $M$. incognita at $8.71 \mu \mathrm{M}$ within $12 \mathrm{~h}$. The number of hatched juveniles per egg mass after 3 days was just 8.44 when treated with $26.14 \mu \mathrm{M}$ cyclohexanamine. This study is the first to demonstrate the nematicidal activity of VOCs produced by D. flagrans against M. incognita, which indicates that $D$. flagrans has the potential to biocontrol plant root-knot nematodes.
\end{abstract}

Keywords: nematode-trapping fungi; Duddingtonia flagrans; Meloidogyne incognita; VOCs; cyclohexanamine; egg hatching

\section{Introduction}

Plant parasitic nematodes infect a variety of crops and cause severe damage, which leads to annual economic losses estimated at \$173 billion [1]. Among plant parasitic nematodes, root-knot nematodes (Meloidogyne spp.) cause the greatest losses in agriculture [2]. Chemical nematicides have been used to control them for a long time, which has led to resistance in nematodes and caused environmental problems. Biological control is an effective and popular method for reducing the parasite population because it does not have an impact on the environment. Nematophagous fungi, natural enemies of plant parasitic nematodes, have been suggested as promising resources for the biological control of nematodes. They can exist in diverse environments, and some of them can switch from being saprotrophic to predatory when nematodes are present [3]. Nematophagous fungi include four major groups; namely, trapping, endoparasitic, opportunistic, and toxic fungi [4-6]. Among them, nematode-trapping fungi (NTF) can produce diverse trap devices containing adhesive network, branches, knobs and constricting or non-constricting rings to capture nematodes [7].

Duddingtonia flagrans is a representative species of NTF and belongs to the family Orbiliaceae of Ascomycota. It forms three-dimensional adhesive networks that trap the nematodes. Duddingtonia flagrans is considered as a promising fungal species for the biological control of animal endoparasites as several reports showed its effectiveness in the control of gastrointestinal parasites [8-11]. Duddingtonia flagrans has attractive potential 
as a biocontrol agent, because it can easily produce a large quantity of chlamydospores that are appropriate for dissemination in the environment [3]. However, to date, there have been few reports on the use of this fungus to control plant-parasitic nematodes. A $D$. flagrans isolate was assessed for its trapping efficiency against the root-knot nematode Meloidogyne spp. [12]. Subsequently, Monteiro et al. proved that D. flagrans reduced 72.7\% of juveniles of Meloidogyne javanica at a concentration of 8201 chlamydospores per gram of soil [13], which illustrates the ability to control plant parasitic nematodes of the species. Hence, D. flagrans has the potential to be developed as a biological control agent against plant parasitic nematodes. However, there is no information about the predatory process of this fungal species on the plant's parasitic nematode. In addition to controlling nematodes, D. flagrans can promote growth and phosphorus use efficiency in tomato plants, which increases its potential uses [14].

Many microorganisms and their metabolites have shown great potential for the control of nematodes. Volatile organic compounds (VOCs) are natural small volatile substances that are generally less toxic and have great potential for application as biological control agents [15]. Nematicidal VOCs produced by microorganisms are thus considered promising molecules to develop nematicides. Many nematicidal VOCs have been identified in fungi. 2-Methylbutyl acetate, 3-methylbutyl acetate, ethyl acetate, and 2-methylpropyl acetate are the main VOCs produced by Fusarium oxysporum, which are active against plant parasitic nematodes [16]. Liarzi, et al. found that the fungus Daldinia cf. concentrica produces nematicidal VOCs that can control the root-knot nematode $M$. javanica, both in vitro and in greenhouse experiments, and demonstrated that 4-heptanone was the major active component [17]. Li, et al. detected the volatile substances released by Annulohypoxylon sp. FPYF3050; among them being 1,8-cineole, which showed strong activity against the pine wood nematode Bursaphelenchus xylophilus [18]. To date, there are many nematicidal metabolites reported from NTF [19], but few about VOCs. In D. flagrans, three metabolites, namely, flagranones A, B, and C, were found, and these compounds displayed antimicrobial activity [20].

In the present study, the predatory process of $D$. flagrans against the plant parasitic nematode $M$. incognita was observed using scanning electron microscopy (SEM). Based on the analysis of gas chromatography-mass spectrometry (GC-MS) and confirmation with commercial compounds, three compounds (cyclohexanamine, cyclohexanone, and cyclohexanol) were toxic to both juveniles and eggs of $M$. incognita. This implies that the NTF D. flagrans can infect nematodes by shaping the trap device and producing active metabolites.

\section{Materials and Methods}

\subsection{Materials and Normal Culture}

D. flagrans (CBS565.50) was deposited in the culture collection of the Key Laboratory for Conservation and Utilization of Bio-resource, and Key Laboratory for Microbial Resources of the Ministry of Education, Yunnan University. The strain was initially maintained on potato dextrose agar (PDA, $200 \mathrm{~g}$ potato, $20 \mathrm{~g}$ dextrose, $20 \mathrm{~g}$ agar, $1 \mathrm{~L}$ water, $\mathrm{pH}$ 7.0) slants at $4{ }^{\circ} \mathrm{C}$. The strain was transferred to PDA plates at $28^{\circ} \mathrm{C}$ for 7 days and then inoculated into $250 \mathrm{~mL}$ triangular flasks, each containing corn medium $(70 \mathrm{~g}$ corn kernels and $70 \mathrm{~mL}$ water in a $250 \mathrm{~mL}$ flask). In the solid medium, the strain was cultured at $28^{\circ} \mathrm{C}$ for 20 days. The cultures $(5 \mathrm{~g})$ were taken out and put into another sterilized $50 \mathrm{~mL}$ flask, and $5 \mathrm{~mL} \mathrm{ddH} \mathrm{H}_{2} \mathrm{O}$ were added to rinse chlamydospores.

In the volatile experiment, the strain cultured on PDA medium was transferred into a $250 \mathrm{~mL}$ flask containing $100 \mathrm{~mL}$ of yeast extract peptone dextrose medium (YPD, $20 \mathrm{~g}$ peptone, $10 \mathrm{~g}$ yeast extract, $20 \mathrm{~g}$ dextrose, $1 \mathrm{~L}$ water). The liquid cultures were incubated in a rotary shaker $(180 \mathrm{rpm})$ at $28{ }^{\circ} \mathrm{C}$ for 5 days as a seed. Then, $2 \mathrm{~mL}$ of seed was added to a $250 \mathrm{~mL}$ flask containing $100 \mathrm{~mL}$ of YPD medium and incubated at $180 \mathrm{rpm}$ at $28^{\circ} \mathrm{C}$ for 14 days. Fungal cultures were used in the subsequent experiments. 
M. incognita egg masses were collected from the roots of infested tomato plants. The method for isolating nematodes from roots refers to reference [21]. The egg masses were incubated at room temperature to obtain juveniles that were collected and prepared in distilled water as a suspension to use.

\subsection{Observation of Trap Formation and Predatory Process Using Scanning Electron Microscopy}

The trap formation and pathogenicity of $D$. flagrans against $M$. incognita were observed using SEM. Dialysis membrane discs $(3 \mathrm{~cm}$ in diameter) were placed on the surface of water agar medium (WA, $2 \%$ agar-water) in $3 \mathrm{~cm}$ diameter Petri dishes. Two microliters of chlamydospores (approximately 150-200) were covered on the surface of the WA medium and evenly distributed on the surface of the dialysis membrane using a spreader. These Petri dishes were then incubated at $28^{\circ} \mathrm{C}$. After four days, Petri dishes were removed from the incubator and suspension containing approximately 200-300 J2s of M. incognita was added to the $D$. flagrans. These Petri dishes were then incubated continuously at $28{ }^{\circ} \mathrm{C}$. Pieces of dialysis membranes were collected at 12, 24, and $48 \mathrm{~h}$ after inoculation with M. incognita and cut with a scalpel. The samples were prepared based on the method described by Wan et al., 2021 [22] and observed using a scanning electron microscope.

\subsection{Gas Chromatography-Mass Spectrometry Assay}

The fermentation broth of $D$. flagrans cultured on YPD medium was extracted with cyclohexane, dehydrated using anhydrous sodium sulfate, and then quickly concentrated using a rotary evaporator at low temperature and negative pressure. The VOC components of the samples were analyzed by GC-MS (7890A-5975C GC-MS system, Agilent Technologies, Santa Clara, CA, USA). The VOCs were identified from a database comparison of the mass spectrum of the substance with data banks (NIST) [23].

All commercial compounds were purchased from Macklin (Shanghai, China) with a purity of $\geq 98 \%$. The following chemicals were used: cyclohexanol $(\geq 98.5 \%)$, cyclohexanone $(98 \%)$, cyclohexanamine $(98 \%)$, heptane $(\geq 98 \%)$, 2-pyrrolidinone $(99.5 \%)$, benzeneethanol $(91 \%)$, tetradecane $(98 \%), 1$-dodecanol $(95 \%)$, cyclododecane $(99 \%)$, 9octadecenoic acid (99\%) and tetracosane (99\%).

\subsection{Assays of Nematicidal Activity}

2.4.1. Nematicidal Activity of the Broth's VOCs and Compounds

Broth $(200 \mu \mathrm{L})$ cultured in YPD medium, or each commercial VOC at the different doses was added to one well in the center of a 96-well plate respectively; $100 \mu \mathrm{L}$ of nematode suspension in $\mathrm{ddH}_{2} \mathrm{O}$ (approximately 100-200 worms) were added to the eight wells adjacent to the test sample [24]. The YPD medium $(200 \mu \mathrm{L})$ was used as a control for the culture filtrate $(200 \mu \mathrm{L})$ of $D$. flagrans. In the experiment with commercial VOCs, no control was used. The plates were immediately wrapped in Parafilm. All plates were incubated at $25^{\circ} \mathrm{C}$ for 6,12 , and $24 \mathrm{~h}$. Mobile and immobile juveniles were counted under a microscope. Meloidogyne incognita was considered dead when no movement was observed after it was touched with a needle. The experiment was repeated three times.

The corrected mortality of M. incognita was calculated using Schneider-Corelli's formula [25]. The data in Figure 3A performed a Student $t$ test on the control and broth at each time point. Different letters indicate that there is a significant difference between the control and the broth at this time point when $p<0.05$. The experimental data were averaged and analyzed by SPSS 20. Comparison between groups was analyzed through single-factor ANOVA. LSD was used in post-hoc test.

\subsubsection{Inhibition of Egg Hatching Activity by VOCs}

The broth and VOCs were tested for the inhibition of the egg hatching activity of M. incognita. Egg masses were collected from the infested roots. The experiments were performed in 96-well plates. Broth and each VOC (the concentration of each compound was varied and determined according to its activity result) were added to one well in the 
center of a 96-well plate independently. An egg mass was placed in distilled water and added to one well adjacent to the sample (altogether eight wells), respectively [26]. The plates were incubated at $25^{\circ} \mathrm{C}$. The numbers of hatched juveniles were counted under a microscope after 1, 2, and 3 days. Each treatment was performed in triplicate and data analysis was the same as above.

\section{Results}

\subsection{Trap Formation and Pathogenicity Process of D. flagrans against M. incognita}

NTF D. flagrans produces three-dimensional adhesive networks that trap nematodes. The trap formation and predatory process of $D$. flagrans against $M$. incognita were recorded using SEM. After nematodes were added to $D$. flagrans for $12 \mathrm{~h}$, a simple loop formed from vegetative hypha, or at least two-thirds of a loop was formed (Figure 1A). New hyphal connections from the simple loop, or from another branch of the vegetative hyphae (Figure 1B), were observed. This resulted in the formation of a three-dimensional capture structure (Figure 1C). At the same time, many adhesive networks were observed (Figure 1D,E), and several nematodes were caught by the traps (Figure 1F).

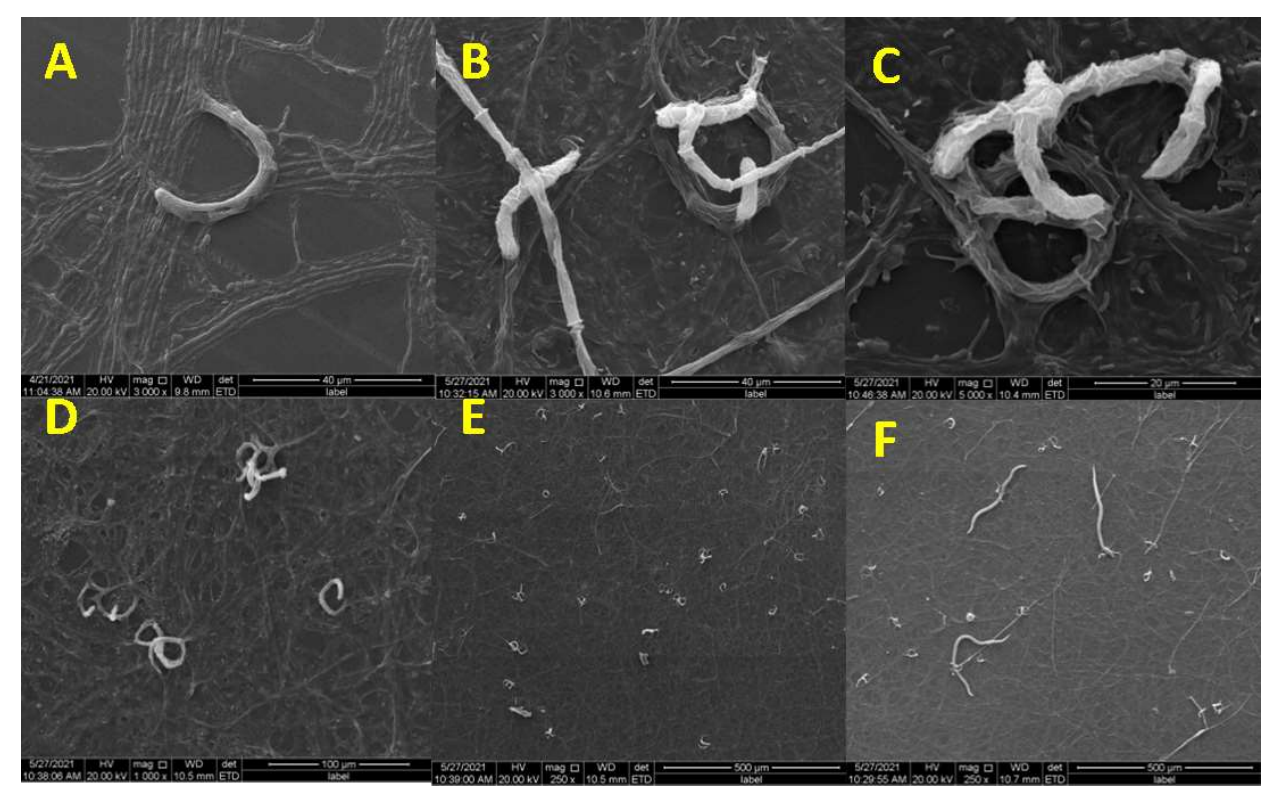

Figure 1. Trap (adhesive three-dimensional network) formation of D. flagrans. (A) The loop was formed; (B) The connection of hyphal and loop; (C) The formation of a three-dimensional capture structure; (D) and (E): Many adhesive networks; (F) The captured nematodes.

The nematodes were captured by the loops $12 \mathrm{~h}$ after inoculation of the fungus with M. incognita. At $24 \mathrm{~h}$, many nematodes were trapped by at least one loop in a variety of locations, including their cephalic portion, body, or tail (Figure 2A). Different portions were even trapped at the same time (Figure $2 \mathrm{~B}$ ). With the advance of the predatory process, an increasing number of $M$. incognitas were captured and killed by traps, and an increase in the size of the three-dimensional network was observed (Figure 2C). In addition, we found that some nematodes adhered to the surface of the capture structure (Figure 2D), indicating that adhesive substances played an important role in the pathogenicity process. After $48 \mathrm{~h}$, most nematodes died and were destroyed during the interaction process with $D$. flagrans (Figure 2E). This is similar to the predatory process of D. flagrans against Ancylostoma spp. of nematodes [27]. In addition, some nematodes twined by mycelia were observed in the pathogenicity process (Figure $2 \mathrm{~F}$ ). 


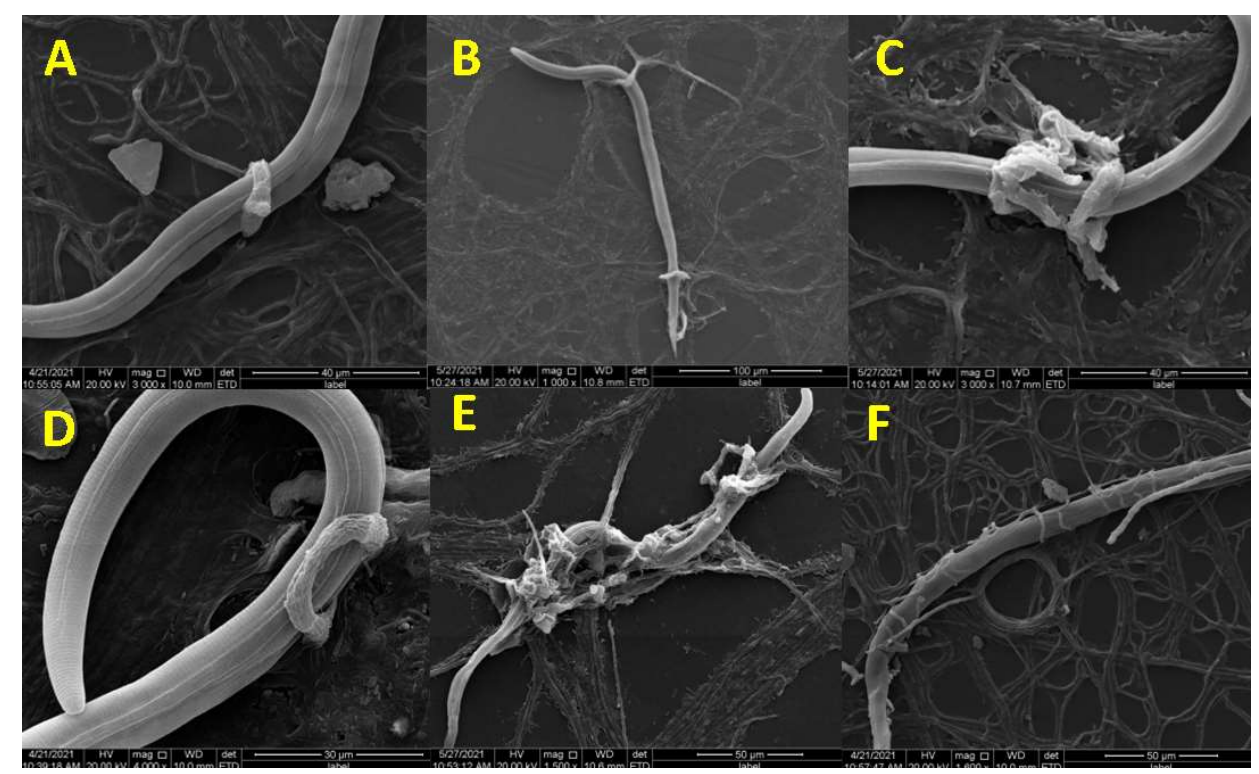

Figure 2. The pathogenicity process of $D$. flagrans against $M$. incognita. (A) The nematode was trapped by one loop; (B) The nematode was trapped at different portions; (C) The expanded three-dimensional network; (D) The nematode was adhered at the surface of the trap; (E) The dead nematode; (F) The nematode was twined by mycelia.

\subsection{Nematicidal Activity of D. flagrans' Broth VOCs against M. incognita}

D. flagrans was cultured in YPD medium for 14 days. The nematicidal activity of VOCs, produced by $D$. flagrans, was assayed in a 96-well plate. It showed strong activity against $M$. incognita (Figure 3). It caused $78.10 \%$ mortality at $24 \mathrm{~h}$, which was much higher than that of the medium control (Figure 3A). The results revealed that D. flagrans could produce VOCs to kill M. incognita.

\subsection{Identification of the VOCs Produced by D. flagrans}

According to the GC-MS results, 52 VOCs were identified in the broth extracts of D. flagrans (Supplementary File). Eleven main volatile compounds (cyclohexanol, cyclohexanone, cyclohexanamine, heptane, 2-pyrrolidinone, benzeneethanol, tetradecane, 1-dodecanol, cyclododecane, 9-octadecenoic acid and tetracosane) were selected mainly based on area percentage. These 11 metabolites were considered as the active candidates, and their nematicidal effects were assayed, using commercial compounds.

\subsection{Nematicidal Activity of VOCs against M. incognita}

The activity of VOCs against $M$. incognita was tested in 96-well plates. At a dose of 10 $\mu \mathrm{L}$, three of the 11 tested candidates (cyclohexanol, cyclohexanone and cyclohexanamine) exhibited strong nematicidal activity against $M$. incognita (Figure 3B). Cyclohexanone and cyclohexanamine caused $100 \%$ mortality of $M$. incognita at $12 \mathrm{~h}$. However, the other eight metabolites showed no obvious activity at $10 \mu \mathrm{L}$ (Supplementary File). Subsequently, the activity of cyclohexanone and cyclohexanamine against $M$. incognita was further tested at lower doses, respectively. The results showed that the activity of cyclohexanone and cyclohexanamine was still strong at a dose of 9.67 and $8.71 \mu \mathrm{M}$, respectively, which led to $86.65 \%$ and $97.93 \%$ death rate, respectively, at $12 \mathrm{~h}$ (Figure 3C,D). 

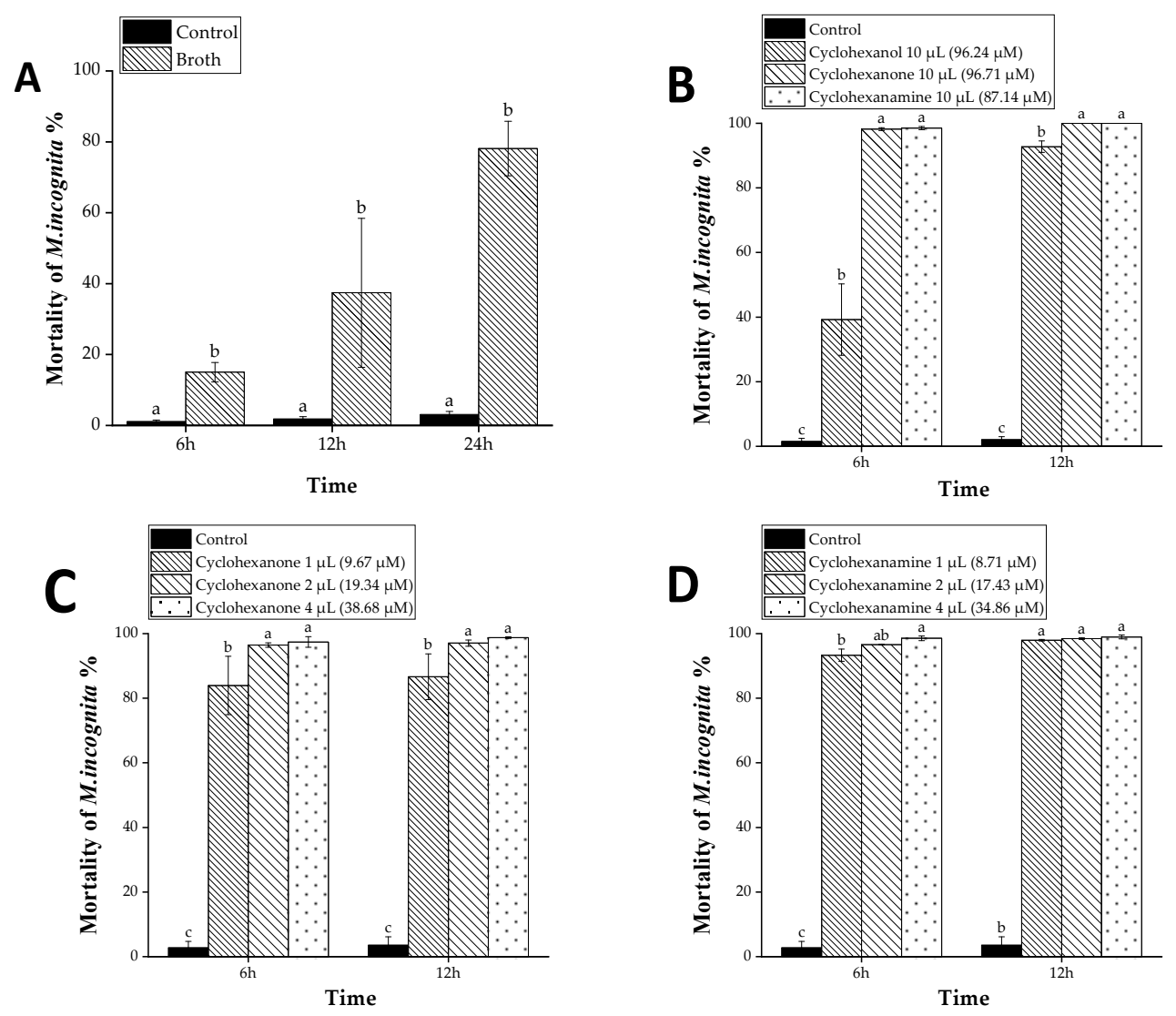

Figure 3. Nematicidal activity of VOCs produced by $D$. flagrans against $M$. incognita. Values with the same lowercase letters in the figure have no difference when $p<0.05$; bars indicate the standard error of the means $(n=3)$. (A) The mortality of nematodes treated with broth and control; (B) The mortality of nematodes treated with cyclohexanol, cyclohexanone and cyclohexanamine; (C) The mortality of nematodes treated with different doses of cyclohexanone; (D) The mortality of nematodes treated with different doses of cyclohexanamine.

\subsection{Inhibition of Egg Hatching by VOCs}

The inhibition of egg hatching by VOCs from the broth was tested. The number of nematodes was much lower within the presence of VOCs, than that in the medium control. The average number of hatched juveniles per egg mass after 3 days of treatment with VOCs from the broth was 15.35; whereas the average number under the control treatment was 99.72 (Table 1).

Table 1. Effects of three VOCs and culture broth on egg hatching of M. incognita.

\begin{tabular}{|c|c|c|c|}
\hline & \multicolumn{3}{|c|}{ Hatched Worms per Egg Mass \pm SD } \\
\hline & 1 Day & 2 Days & 3 Days \\
\hline Cyclohexanol $96.24 \mu \mathrm{M}$ & $29.13 \pm 5.95 b$ & $30.41 \pm 4.87 b$ & $30.69 \pm 4.59 \mathrm{~b}$ \\
\hline Cyclohexanone $96.71 \mu \mathrm{M}$ & $2.25 \pm 0.82 \mathrm{~d}$ & $3.14 \pm 0.33 \mathrm{~d}$ & $3.14 \pm 0.33 \mathrm{~d}$ \\
\hline Cyclohexanone $48.36 \mu \mathrm{M}$ & $10.01 \pm 1.21 \mathrm{~cd}$ & $10.14 \pm 1.23 \mathrm{~cd}$ & $10.14 \pm 1.23 c$ \\
\hline Cyclohexanamine $26.14 \mu \mathrm{M}$ & $7.00 \pm 1.21 \mathrm{~cd}$ & $8.18 \pm 0.64 \mathrm{~cd}$ & $8.44 \pm 0.69 \mathrm{~cd}$ \\
\hline Culture broth $200 \mu \mathrm{L}$ & $14.13 \pm 4.02 \mathrm{c}$ & $14.92 \pm 4.01 \mathrm{c}$ & $15.35 \pm 4.24 c$ \\
\hline control & $83.28 \pm 2.76 \mathrm{a}$ & $93.50 \pm 3.05 \mathrm{a}$ & $99.72 \pm 2.71 \mathrm{a}$ \\
\hline
\end{tabular}

The number represents the means of the replicates \pm SD. The same lowercase letters indicate that there is no significant difference between treatments $(p<0.05)$.

The three VOCs, cyclohexanamine, cyclohexanone, and cyclohexanol, were also tested for their inhibitory activity against egg hatching. Cyclohexanamine exhibited the highest 
inhibitory activity. The average number of hatched worms per egg mass after 3 days was 8.44, when treated with $26.14 \mu \mathrm{M}$ cyclohexanamine (Table 1). Another compound, cyclohexanone, also showed strong inhibitory activity. With $96.71 \mu \mathrm{M}$ and $48.36 \mu \mathrm{M}$ cyclohexanone, the average numbers of hatched juveniles per egg mass after 3 days were 3.14 and 10.14, respectively. Among the three VOCs, cyclohexanol showed the weakest inhibitory activity on egg hatching, and the number of hatched juveniles was 30.69 after treatment with $96.24 \mu \mathrm{M}$ of the compound for 3 days.

\section{Discussion}

To date, many effective chemicals used for controlling the root-knot nematodes, Meloidogyne spp., are highly toxic and are gradually being forbidden. Therefore, less toxic nematicidal agents need to be developed. The lack of safer and more effective nematicides has accelerated the search for more natural products. In the last few years, much effort has been focused on the search for natural nematicidal VOCs, because their nematocidal toxicity is considered a possible alternative [28]. The VOCs can affect nematodes by direct contact or fumigation [24]. As a typical NTF, D. flagrans is famous for producing chlamydospores and three-dimensional adhesive networks that capture nematodes. To date, this is the most potential candidate for commercial application. Along with this, the species has been used to control parasite nematodes in animals [10].

SEM was used to observe the predatory process of $D$. flagrans against $M$. incognita. The species infects $M$. incognita by trapping the nematode with adhesive networks. The infection process observation of the species against Haemonchus contortus [29], Strongylus equinus [30], Caenorhabditis elegans [31] and Ancylostoma spp. [27] has been previously reported. This indicates that the species can capture different types of nematodes.

In this study, 52 VOCs were detected from the NTF D. flagrans using GC-MS. We then examined the activity of the 11 abundant VOCs against the root-knot nematode M. incognita. The results showed cyclohexanamine, cyclohexanone, and cyclohexanol were active against both juveniles and eggs. To the best of our knowledge, these molecules have never been tested in bioassays against the root-knot nematode M. incognita. Among them, cyclohexanamine exhibited the highest nematicidal activity, which indicates that NTFs could become an important source of natural nematicides. To date, thousands of VOCs produced by microorganisms have been identified that could result in new nematicides which may lead to new products development [16]. However, laboratory studies are not sufficient as they do not represent the natural environment [32]. Soil-based environmental experiments are required to demonstrate efficacy in situ.

In our study, $D$. flagrans efficiently trapped the plant's parasitic nematode $M$. incognita and also produced VOCs to kill nematodes and inhibit egg hatching of M. incognita. VOC metabolites seem to have a synergistic effect regarding the pathogenic process of NTF $D$. flagrans against $M$. incognita. It has been shown that $D$. flagrans could reduce juveniles of $M$. javanica in soil [13]. These results indicate that $D$. flagrans has the potential to biocontrol plant root-knot nematodes. The biocontrol effects of a mixture of VOCs or a single VOC produced by the fungus, or the strain itself need to be tested further in soil experiments.

Supplementary Materials: The following are available online at https://www.mdpi.com/article/10 $.3390 /$ microorganisms9112268/s1. Supplementary File: The GC-MS data and nematicidal activity of metabolites.

Author Contributions: Conceptualization, X.M. and G.L.; methodology, X.M. and G.L.; software, X.M.; validation, X.W. and G.L.; formal analysis, X.M.; investigation, G.L.; resources, G.L.; data curation, X.M. and X.W.; writing-original draft preparation, X.M. and G.L.; writing-review and editing, X.M. and G.L.; supervision, G.L.; project administration, X.W. and G.L.; funding acquisition, G.L. All authors have read and agreed to the published version of the manuscript.

Funding: This research was funded by the National Natural Science Foundation of China (31860015 and 32160012) and projects from the Department of Science and Technology of Yunnan Province (202001BB050061). 
Institutional Review Board Statement: Not applicable.

Informed Consent Statement: Not applicable.

Data Availability Statement: Not applicable.

Conflicts of Interest: The authors declare no conflict of interest.

\section{References}

1. Elling, A.A. Major emerging problems with minor Meloidogyne species. Phytopathology 2013, 103, 1092-1102. [CrossRef]

2. Oka, Y.; Koltai, H.; Bar-Eyal, M.; Mor, M.; Sharon, E.; Chet, I.; Spiegel, Y. New strategies for the control of plant-parasitic nematodes. Pest Manag. Sci. 2000, 56, 983-988. [CrossRef]

3. Youssar, L.; Wernet, V.; Hensel, N.; Yu, X.; Hildebrand, H.G.; Schreckenberger, B.; Kriegler, M.; Hetzer, B.; Frankino, P.; Dillin, A.; et al. Intercellular communication is required for trap formation in the nematode-trapping fungus Duddingtonia flagrans. PLoS Genet 2019, 15, e1008029. [CrossRef] [PubMed]

4. Pandit, R.; Patelm, R.; Patel, N.; Bhatt, V.; Joshi, C.; Singh, P.K.; Kunjadia, A. RNA-Seq reveals the molecular mechanism of trapping and killing of root-knot nematodes by nematode-trapping fungi. World J. Microbiol. Biotechnol. 2017, 33, 65. [CrossRef]

5. Nordbring-Hertz, B.; Jansson, H.B.; Tunlid, A. Nematophagous Fungi. Encyclopedia of Life Sciences; John Wiley \& Sons, Ltd.: Hoboken, NJ, USA, 2006.

6. Lopez-Llorca, L.V.; Olivares-Bernabeu, C.; Salinas, J.; Jansson, H.B.; Kolattukudy, P.E. Prepenetration events in fungal parasitism of nematode eggs. Mycol. Res. 2002, 106, 499-506. [CrossRef]

7. Yang, Y.; Yang, E.; An, Z.; Liu, X. Evolution of nematode-trapping cells of predatory fungi of the Orbiliaceae based on evidence from rRNA-encoding DNA and multiprotein sequences. Proc. Natl. Acad. Sci. USA 2007, 104, 8379-8384. [CrossRef]

8. Hertzberg, H.; Larsen, M.; Maurer, V. Biological control of helminths in grazing animals using nematophagous fungi. Berl. Munch Tierarztl. Wochenschr. 2001, 115, 278-285.

9. Sahoo, A.; Khan, F. Nutritional and biological control synergism against gastrointestinal nematodes in small ruminants. J. Vet Sci. Anim. Husb. 2016, 4, 104.

10. Cai, K.Z.; Liu, J.L.; Liu, W.; Wang, B.B.; Xu, Q.; Sun, L.J.; Chen, M.Y.; Zhao, M.W.; Wu, J.Y.; Li, X.S. Screening of different sample types associated with sheep and cattle for the presence of nematophagous fungi in China. J. Basic Microbiol. 2016, 56, 214-228. [CrossRef]

11. Céspedes-Gutiérrez, E.; Aragón-Novoa, D.M.; Gómez-Lvarez, M.I.; Cortés-Rojas, D.F. In vitro evaluation of physicochemical variables on the nematophagous fungus Duddingtonia flagrans. J. Basic Microbiol. 2021, 61, 547-556. [CrossRef]

12. Pandit, R.J.; Kunjadia, P.D.; Mukhopadhyaya, P.N.; Joshi, C.G. Isolation, molecular characterization and predatory activity of two Indian isolates of nematode-trapping fungi. Appl. Biol. Res. 2014, 16, 1-11. [CrossRef]

13. Monteiro, T.S.A.; Balbino, H.M.; de Mello, I.N.K.; Coutinhoa, R.R.; de Araújo, J.V.; Freitasa, L.G. Duddingtonia flagrans preying a plant parasitic nematode. Braz. J. Biol. 2020, 80, 197-198. [CrossRef]

14. Monteiro, T.S.A.; Valadares, S.V.; de Mello, I.N.K.; Moreira, B.C.; Kasuya, M.C.M.; de Araújo, J.V.; de Freitas, L.G. Nematophagus fungi increasing phosphorus uptake and promoting plant growth. Biol. Control 2018, 123, 71-75. [CrossRef]

15. Campos, V.P.; Pinho, R.S.C.; Freire, E.S. Volatiles produced by interacting microorganisms potentially useful for the control of plant pathogens. Ciênc E Agrotecnol. 2010, 34, 525-535. [CrossRef]

16. Terra, W.C.; Campos, V.P.; Martins, S.J.; Costa, L.S.A.S.; da Silva, J.C.P.; Barros, A.F.; Lopez, L.E.; Santos, T.C.N.; Smant, G.; Oliveira, D.F. Volatile organic molecules from Fusarium oxysporum strain 21 with nematicidal activity against Meloidogyne incognita. Crop Prot. 2018, 106, 125-131. [CrossRef]

17. Liarzi, O.; Bucki, P.; Miyara, S.B.; Ezra, D. Bioactive volatiles from an endophytic Daldinia cf. concentrica isolate affect the viability of the plant parasitic nematode Meloidogyne javanica. PLoS ONE 2016, 11, e0168437. [CrossRef] [PubMed]

18. Li, H.; Dou, G.; Gao, M.; Ren, F.; Li, R.; Zhang, X.; Yan, D.H. Annulohypoxylon sp. FPYF3050 produces volatile organic compounds against the pine wood nematode, Bursaphelenchus xylophilus. Nematology 2020, 22, 245-255. [CrossRef]

19. Degenkolb, T.; Vilcinskas, A. Metabolites from nematophagous fungi and nematicidal natural products from fungi as an alternative for biological control. Part I: metabolites from nematophagous ascomycetes. Appl. Microbiol. Biotechnol. 2016, 100, 3799-3812. [CrossRef]

20. Anderson, M.G.; Rickards, R.W.; Lacey, E. Structures of flagranones A, B and C, cyclohexenoxide antibiotics from the nematodetrapping fungus Duddingtonia flagrans. J. Antibiot. 1999, 53, 1023-1028. [CrossRef]

21. Lee, Y.S.; Naning, K.W.; Nguyen, X.H.; Kim, S.B.; Moon, J.H.; Kim, K.Y. Ovicidal activity of lactic acid produced by Lysobacter capsici YS1215 on eggs of root-knot nematode, Meloidogyne incognita. J. Microbiol. Biotechnol. 2014, 24, 1510-1515. [CrossRef]

22. Wan, J.; Dai, Z.; Zhang, K.; Li, G.; Zhao, P. Pathogenicity and metabolites of endoparasitic nematophagous fungus Drechmeria coniospora YMF1.01759 against nematodes. Microorganisms 2021, 9, 1735. [CrossRef] [PubMed]

23. Su, H.N.; Xu, Y.Y.; Wang, X.; Zhang, K.Q.; Li, G.H. Induction of trap formation in nematode-trapping fungi by bacteria-released ammonia. Lett. Appl. Microbiol. 2016, 62, 349-353. [CrossRef] [PubMed]

24. Huang, D.; Yu, C.; Shao, Z.; Cai, M.; Li, G.; Zheng, L.; Yu, Z.; Zhang, J. Identification and characterization of nematicidal volatile organic compounds from deep sea Virgibacillus dokdonensis MCCC 1A00493. Molecules 2020, 25, 744. [CrossRef] 
25. Ntalli, N.G.; Ferrari, F.; Giannakou, I.; Menkissoglu-Spiroudi, U. Synergistic and antagonistic interactions of terpenes against Meloidogyne incognita and the nematicidal activity of essential oils from seven plants indigenous to Greece. Pest Manag. Sci. 2011, 67,341-351. [CrossRef]

26. Zhai, Y.; Shao, Z.; Cai, M.; Zheng, L.; Li, G.; Huang, D.; Cheng, W.; Thomashow, L.S.; Weller, D.M.; Yu, Z.; et al. Multiple modes of nematode control by volatiles of Pseudomonas putida 1A00316 from Antarctic soil against Meloidogyne incognita. Front. Microbiol. 2018, 9, 253. [CrossRef] [PubMed]

27. Maciel, A.S.; Araújo, J.V.; Campos, A.K.; Benjamin, L.A.; Freitas, L.G. Scanning electron microscopy of Ancylostoma spp. dog infective larvae captured and destroyed by the nematophagous fungus Duddingtonia flagrans. Micron 2009, 40, 463-470. [CrossRef]

28. Andrés, M.F.; González-Coloma, A.; Sanz, J.; Burillo, J.; Sainz, P. Nematicidal activity of essential oils: a review. Phytochem. Rev. 2012, 11, 371-390. [CrossRef]

29. Campos, A.K.; Araújo, J.V.; Guimares, M.P. Interaction between the nematophagous fungus Duddingtonia flagrans and infective larvae of Haemonchus contortus (Nematoda: Trichostrongyloidea). J. Helminthol. 2008, 82, 337-341. [CrossRef] [PubMed]

30. Li, J.Y.; Luo, H.L.; Wangm, R.; Yang, L.R.; Zhao, Z.G.; Zhang, W.; Li, B.; Yang, X.Y.; Luo, X.P. Observation on predatory process of Duddingtonia flagrans against infective larvae of Strongylus equinus. Progress Vet. Med. 2018, 39(10), $122-125$.

31. Xu, C.L.; Liu, W.; Li, Y.Q.; Wang, K.Y.; Qin, G.G.; Wang, D.M.; Wang, B.B.; Wang, H.; Li, X.; Yi, L.X. Observation dynamics of Duddingtonia flagrans against infective larvae of Haemonchus contortus and free-living nematode Caenorhabditis elegans. Chin. Vet. Sci. 2014, 44, 1119-1126.

32. Kanchiswamy, C.N.; Malnoy, M.; Maffei, M.E. Chemical diversity of microbial volatiles and their potential for plant growth and productivity. Front. Plant Sci. 2015, 6, 1-23. [CrossRef] [PubMed] 